\title{
Implicit Learning in Children Is Not Related to Age: Evidence from Drawing Behavior
}

\author{
Annie Vinter and Pierre Perruchet
}

\begin{abstract}
Three experiments are reported on implicit learning in 432 children between the ages of 4 and 10 years, using a new paradigm ("the neutral parameter procedure") based on drawing behavior. The first two experiments demonstrated that children modified their drawing behavior following specially devised practice in such a way that these modifications could not be viewed as the result of deliberate adaptive strategies. The third experiment showed that these behavioral modifications lasted for at least $1 \mathrm{hr}$ after the training phase. No agerelated differences appeared in the experiments. A comparison of children's data with similar adults' data also failed to reveal any age differences. These results provide compelling evidence that implicit learning processes are age independent. Some implications of these results for developmental issues are discussed, notably the hypothesis of the formation of implicit knowledge in the course of learning.
\end{abstract}

\section{INTRODUCTION}

The fundamental role of learning, neglected by cognitive psychologists a few decades ago, is now acknowledged in most areas of research, including language, categorization, and object perception (Bates \& Elman, 1996). Of course, nobody has ever claimed that language development is independent of infants' experience. The dominant Chomskian tradition, however, has confined learning to subsidiary functions, such as setting the values of parameters in a hard-wired system. Recent work shows that fundamental components of language such as word segmentation (Saffran, Newport, Aslin, Tunick, \& Barrueco, 1997) can be learned in an incidental way similar to that involved in the acquisition of other human abilities. Likewise, it has never been denied that learning plays a role in categorization and object perception, but acquisition processes were thought to be limited to new combinations of preestablished features (e.g., Bruner, Goodnow, \& Austin, 1956). Schyns and Rodet (1997) have shown, however, that elementary features can themselves be created with experience (for a review, see Schyns, Goldstone, \& Thibaut, 1998).

The type of learning process that receives the most attention in the current literature relates to implicit learning. Different definitions of implicit learning have been proposed (e.g., Berry \& Dienes, 1993; Reber, 1989), most involving the idea that implicit learning contributes to the formation of an implicit knowledge base, dissociated from explicit knowledge (see Seger, 1994, for a review subscribing to this view). We propose a definition that is neutral with regard to the issue of the nature of the resulting knowledge. In our view, implicit learning designates an adaptive mode in which children's behavior becomes sensitive to the structural features of an experienced situation, without the adaptation being due to an intentional exploitation of some pieces of explicit knowledge about these features (Perruchet \& Vinter, 1998). The two important components of implicit learning are thus the behavioral sensitivity to the structure of the situation and the lack of intentional causes for this sensitivity.

\section{Implicit Learning Processes in Development}

Clearly, a large proportion of the motor, perceptive, and cognitive acquisitions made by children in the course of development results from learningand more specifically from implicit learning processes. Implicit learning has been seen as responsible for at least some aspects of first-language (e.g., Chandler, 1993) and second-language learning (e.g., Carr \& Curran, 1994), category elaboration, reading and writing acquisition, adaptation to the physical constraints of the world (e.g., Krist, Fieberg, \& Wilkening, 1993), and acquisition of social skills (Reber, 1993). Most of this learning takes place during infancy and childhood and constitutes the essential core of what a newborn must acquire to become an adult. This is why the idea of the primacy of implicit learning processes, initially claimed by Reber (1993), has been by and large tacitly adopted by most authors working in the implicit learning domain.

Developmental psychologists also consider that implicit learning processes play an important role in development. Karmiloff-Smith's model (1992) postulates that the first phase achieved in each domain of

(C) 2000 by the Society for Research in Child Development, Inc. All rights reserved. 0009-3920/2000/7105-0012 
competence corresponds to a level of behavioral mastery involving implicit knowledge, formed by datadriven processes. Explicit knowledge would be developed during a second phase, through the action of an endogenous process of representational redescription. The distinction between implicit and explicit knowledge is present in several other developmental models (for a review, see Mandler, 1998) and appears to be basic to developmental studies of memory (e.g., Kail, 1990). Moreover, highlighting the fundamental role of bottom-up processes, as can be observed in the dynamical theories (Thelen \& Smith, 1994) or in connectionist modeling (e.g., Elman et al., 1996; Munakata, McClelland, Johnson, \& Siegler, 1997) also attests to the major interest that developmentalists attribute to implicit learning processes in the formation of new adaptive behavior.

Despite this role accorded to implicit learning processes, the developmental literature on this domain remains sparse, whereas a great deal of work has been done on implicit memory (see, e.g., Graf, 1990; Schacter \& Moscovitch, 1984). Hitherto, only a few studies have been devoted to this domain. Moreover, nothing clear is known about the possible age-related specificity of implicit learning processes. Reber (1993) has made the assumption that these processes are age independent, but the results of the few current studies appear contradictory in this respect.

Gomez and Gerken (1999) used a classical paradigm in implicit learning, the artificial grammar paradigm (Reber, 1967), with infants aged approximately 12 months. In this paradigm, participants are usually exposed to a subset of grammatical strings generated by a finite state grammar, where the strings can be composed of printed consonants. The grammar defines the transition rules between events. Participants are then tested to see whether they can discriminate between new grammatical and nongrammatical strings. To adapt this approach for use with infants, Gomez and Gerken's study used auditory syllables instead of printed letters. These syllables were combined according to the rules of an artificial grammar to form legal sequences, which were repeated several times during training. Infants were tested with familiar or new legal sequences and with illegal sequences. The results showed that the infants displayed longer orientation times toward familiar or new legal strings than toward nongrammatical strings, which suggests that they became sensitive to at least some aspects of the structure of the training set. Note that this study not only demonstrates that the implicit learning of an artificial grammar is efficient at a very early age but also suggests that these learning processes are probably involved in language acquisition. A similar con- clusion can be achieved from a study of incidental learning of word segmentation conducted by Saffran et al. (1997) in infants. More recently, Saffran, Johnson, Aslin, and Newport (1999) have shown that 8-month-old infants are able to use the same learning mechanisms to segment sequences of nonlinguistic stimuli. The efficiency of implicit learning processes early in development (4-5 years) has also been revealed in two other studies, one performed by Lewicki (1986), and one by Czyzewska et al. (cited in Lewicki, Hill, \& Czyzewska, 1992).

Meulemans, Van der Linden, and Perruchet (1998) compared the performance of children aged 6-7 years and 10-11 years and adults in an implicit learning task. They used the classical serial reaction time task (Nissen \& Bullemer, 1987), where participants had to respond as quickly as possible to the appearance of a target at one of four locations on a screen by pressing one of four keys corresponding to the position of the target. Without their knowing it, participants were shown a repeating sequence of target appearances, with some intermixed random trials. Regardless of age, reaction times improved on the repeated sequence when compared with the random parts, thus demonstrating that 6-year-old children learned the sequence as well as adults. Moreover, children and adults improved their performance on the same parts of the sequence, a finding that gives additional support to the claim that implicit learning is age insensitive. A study performed by Roter (cited in Reber, 1993), also confirms this view. No agerelated differences in an artificial grammar task were obtained in connection with the implicit performances of children aged 6-7 years, 9-11 years, and 12-15 years. This conclusion also concerns studies on implicit learning in aging. Younger adults regularly displayed performances close to those of older adults in implicit tasks, whereas they were better in tasks requiring conscious thought (Howard \& Howard, 1989, 1992; Myers \& Conner, 1992).

However, contradictory results are provided by Maybery, Taylor, and O'Brien-Malone's study (1995), which was directly inspired by Reber's assumptions (1993) of age independence and of IQ independence. Maybery et al. compared two groups of children, one aged 5-7 years, the other 10-12 years, each group including low, medium, and high IQ children. An incidental covariation task adapted from Lewicki (1986) was used. In this task, children had to learn a covariation between the location of a picture in a $4 \times 4$ matrix and two other features: the side from which the experimenter approached them and the color of the matrix board and cover. After training, 10- to 12-year-old children were better at guessing the location of the 
pictures in a subsequent test phase than were 5-7 year-olds. Moreover, the performance displayed by the younger children was not above chance, which indicates that these children did not implicitly learn the covariations. However, as predicted by Reber (1993), implicit learning did not vary with IQ, which was not the case for an explicit task derived from the matrixlearning task.

To sum up, the literature reports contradictory results with regard to the age independence of implicit learning processes. Mayberry and O'Brien-Malone (1998) consider that empirical evidence for this assumption is up to now limited. One possible explanation is that the age effect observed in the Maybery and O'BrienMalone's study was due to a contamination effect of explicit knowledge on performance in the implicit task. The intentional exploitation of explicit knowledge can never be totally ruled out in classical implicit learning paradigms (Shanks \& St. John, 1994). And, of course, if such explicit factors intervene during implicit learning, a global age effect can be expected in performance improvement. It thus appears crucial to use a method avoiding any contamination effect. The present experiments were aimed at exploring this issue of age independence. To this end, in the present experiments we used the "neutral parameter procedure," which had been devised to remove explicit influences on performance (Vinter \& Perruchet, 1999).

\section{Unconscious Nature of Implicit Learning Processes}

Producing evidence for genuine unconscious influences is a far from easy task. One possible strategy consists in assessing directly the knowledge participants may have obtained from the situation. In the developmental domain, only the study by Meulemans, Van der Linden, and Perruchet (1998) has investigated this issue. A dissociation was reported between the implicit behavioral modifications (improvement of the performance in the serial reaction time task) and the explicit knowledge of the repeating sequence. A postexperimental test of recognition failed to reveal any explicit knowledge of the learned sequence. However, as pointed out by the authors themselves and others (Dulany, Carlson, \& Dewey, 1984; Shanks \& St. John, 1994), such a strategy is open to criticism. It seems highly difficult to design a reliable test, and this difficulty raises a problem for most of the situations classically used in implicit learning. Indeed, in these situations, the critical point is that influences expected from conscious knowledge about the relevant aspects of the situation would have exactly the same effects as those induced by unconscious processes.
For instance, in an artificial grammar learning task, if participants explicitly knew at least some of the rules of the grammar, grammaticality judgments requested in the test phase would improve in the same way as would be expected as a consequence of hypothetical unconscious abstraction of the rules. In other words, the behavioral parameter focused on in most studies is not immune to possible influences from an intentional exploitation of knowledge about the task. In these conditions, disentangling the changes possibly due to unconscious influences from those possibly linked to conscious effects is no easy matter.

We therefore recently explored the suitability of a "neutral parameter procedure" (NPP) to study unconscious influences on behavior in adults (Vinter \& Perruchet, 1999). In this procedure, the task requires participants to focus on behavioral components different from those on which the unconscious influences are assessed, and, most importantly, unconscious effects are assessed on a behavioral parameter that is neutral with regard to task achievement. Any possible intentional exploitation of explicit knowledge about the task should a priori have no consequence on this behavioral parameter. This procedure was suggested to complement the methods currently used in the literature for measuring unconscious influences (e.g., Jacoby, 1991; Merikle \& Joordens, 1997).

The task we selected to implement the procedure exploits a natural covariation present in drawing, the "start-rotation principle" (Van Sommers, 1984), which states that the direction of movement in the drawing of closed geometrical figures is dependent on the starting position. Consider a circle for instance. If the starting point is set above a virtual axis going from 11 o' clock to 5 o'clock, subjects predominantly rotate counterclockwise, whereas they draw clockwise for the lower half of the circumference. In a series of experiments (Vinter \& Perruchet, 1999), adults were asked to draw as fast and as accurately as possible over a set of geometrical figures including a point indicating where to start and an arrow specifying how to rotate. The subject's attention was drawn to the speed-accuracy requirements, whereas these parameters were not those on which the unconscious effects were assessed. For one group of participants, the indications violated the start-rotation principle in $80 \%$ of the trials, thus creating a new covariation between starting location and rotation. Following the training phase, the effects of the manipulation were assessed in a test where only the starting location was imposed and where the frequency of occurrence of principleconform responses was measured.

The results revealed that the principle-incongruent training strongly modified the association between 
the direction of rotation and the starting location. It inverted the natural covariation in more than $30 \%$ of the drawings, when compared with a control group who received nondirected training. As shown by a postexperimental cued-recall test, adults failed to reveal any explicit knowledge of the relevant behavioral manipulation. More crucially, even if one assumes that the explicit test failed to fulfill the criteria put forward by Shanks and St. John (1994), the nature of the performance change ensures that unconscious influences were assessed because it constituted a neutral parameter with regard to task achievement. Indeed, whether participants associated a clockwise or a counterclockwise rotation with a top start, for instance, they responded to task instructions equally well. Even if they had become aware of the experimental manipulation, they should have had no a priori reason to intentionally exploit this knowledge because the experimental manipulation had no relevance for their performance in the task. Thus, the NPP appears to provide a powerful tool for studying unconscious influences. In addition, it appears specially wellsuited to investigating the issue of the age independence of implicit learning, because it excludes a priori any contamination effect of explicit factors on performance. The present paper reports three experiments based on the NPP, using the figure-drawing paradigm. Experiments 1 and 2 explored whether an impact of appropriately devised training was observed in children aged 6-10 years and 4-5 years, respectively. A comparison with adults was also included. Experiment 3 investigated whether the induced behavioral modifications would still be present after a 1-hr delay between the training phase and the test phase. Our general hypothesis was that whatever the age, children should modify their drawing behavior after appropriate training, without being aware that they were doing so.

\section{EXPERIMENT 1}

Method

Participants. Two hundred sixty-one right-handed children between 6 and 10 years of age participated in the experiment. They were divided into five age groups $(M=6$ years: $n=57,28$ males, range $=5,9$ 6,3; $M=7.1$ years: $n=45,23$ males, range $=6,11-7,2$; $M=8.3$ years: $n=60,28$ males, range $=7,10-8,3 ; M=9$ years: $n=48,24$ males, range $=8,10-9,2 ; M=10.1$ years: $n=51,30$ males, range $=9,10-10,2)$. The children in each age group were randomly assigned to one of two orders of test. Moreover, for each age and order, the children were randomly assigned to one of three subgroups differing according to their training phase: the principle-congruent group, the principleincongruent group, and the free control group. There were thus between 7 and 10 children per subgroup for each order. None of these children was educationally advanced or retarded or had psychomotor deficits in drawing or handwriting. Each age group corresponded to one school level, the youngest children coming from the first elementary grade.

Material. The experiment was run with a Wacom PL-100V tablet (display size: $19.19 \times 14.39 \mathrm{~cm}$ ), which functions both as a digitizer (temporal sampling at $200 \mathrm{~Hz}$, spatial resolution of $.05 \mathrm{~mm}$ ) and as a monitor screen. It thus provides a natural paper-like interface with children drawing directly on the tablet with a cordless pen over the figures, the screen display of which was managed by appropriate software. Four types of figures were displayed on the tablet: circles $(1.2 \mathrm{~cm}$ diameter $)$, rectangles $(1.2 \times 2.4 \mathrm{~cm})$, squares $(1.2 \times 1.2 \mathrm{~cm})$, and triangles $(1.2 \times 1.2 \times 1.2 \mathrm{~cm})$. They appeared centered inside a square of $4 \times 4 \mathrm{~cm}$, permanently displayed in the central region of the tablet. A starting point, diameter of $.1 \mathrm{~cm}$, was superimposed on each figure. It was located at the same absolute position (top or bottom), whatever the figure. These positions corresponded to the middle of the horizontals for the square and rectangle, to the 12 o' clock/ 6 o'clock positions for the circle, and to the top of the triangle or the middle of its base. The arrows (length of $1 \mathrm{~cm}$ ) indicating the direction of rotation were located $1 \mathrm{~cm}$ above or below the starting point.

Procedure. The entire experimental session comprised a familiarization phase, a training phase, a test phase, and a questionnaire phase. Whatever the group, the children were asked to draw as fast and as accurately as possible over the templates. The figures appeared one at a time on the screen, with a time interval of $500 \mathrm{~ms}$ after the interruption of the recording process by the experimenter when the child had completed the drawing. During this interval, the children were asked to move the pen to a fixed point on the screen. The appearance of a new figure was signaled by an acoustic beep.

The children were introduced to the procedure during a short familiarization period of eight trials before the training phase started. During the training phase, they were asked to trace over a set of 40 figures consisting of 10 repetitions of the four figures. The figures appeared in a fixed order for any given child (e.g., circle, square, triangle, and rectangle), and different orders were used across children. At each age, the children were divided into three groups. The principle-incongruent group received a set of training figures in which the indications combined either a top 
start with a clockwise direction (40\%, i.e., 4 repetitions of each figure) or a bottom start with a counterclockwise direction (40\%), thus violating the startrotation principle in $80 \%$ of the trials (32 out of 40 figures). The remaining 20\% of the trials were congruent with the principle and included both a top start with a counterclockwise rotation $(10 \%$, i.e., one instance of each figure) and a bottom start with a clockwise direction (10\%). The principle-congruent group received a set of training figures organized in the same way as for the principle-incongruent group, except that the proportions of figures that did or did not conform to the principle were inverted ( $80 \%$ conformed to the principle and 20\% did not). Note that in these two first groups, there were as many top as bottom starts over the whole session and as many clockwise as counterclockwise rotations. The distribution of the various combinations of starting point and rotation direction was random across the 10 repetitions of each figure. The third group, a free control group, received a set of training figures without any indications regarding starting location and movement direction. The children in this group were asked to trace over the figures freely, thus providing a baseline value for the spontaneous respect for the start-rotation principle.

A test phase identical for the three groups followed after a $4-5$ min interval. Two tests including 24 items (six repetitions of each figure) were presented to children. In the starting location test, half of the figures presented a top starting location and half a bottom starting location, without any indication regarding the direction. The distribution of the starting points across the repetitions of each figure was random. The children had to trace over this set of 24 figures while respecting the indicated starting point. In the rotation test, half of the figures displayed a clockwise rotation, half a counterclockwise rotation. The children were required to draw over the figures. They were free to start where they wanted, but they had to respect the indicated direction of rotation. The instructions focused on both accuracy and speed, as in the training phase. The order of presentation of the two tests was counterbalanced within each group.

In the final phase, children from the principlecongruent and from the principle-incongruent groups were invited to report anything they might have noticed in the course of the training phase. These free reports were complemented by a cued-recall test in which the children were given a set of figures and asked to state the starting point and the rotation direction as they remembered having seen them during the training phase. The participants had to locate the starting point and the arrow directly on 12 preprinted figures representing a series of one circle, one square, one rectangle, and one triangle three times over.
Results

Performance data. The factors on which ANOVAs were carried out were labeled as follows: Age (5), Order (2: order in which the tests were administered), and Training (3: type of training phase) constituted between-subjects factors; Figure (4) and Test (2: starting point or rotation direction as a cue) defined withinsubjects factors. The ANOVAs were run on the percentages of respect for the principle shown by each child in the two tests. Figure 1 presents the mean percentage of respect for the principle as a function of Age, Training, and Test.

The nature of the training had a clear and significant impact on children's drawing behavior, $F(2,231)=$ $44.4, p<.001$. As illustrated by Figure 1, however, the test using the starting location as a cue revealed a much stronger effect of training in comparison to the test using the rotation direction, as shown by the significant Training $\times$ Test interaction, $F(2,231)=27, p<$ .001. Significance was reached for the starting location test at all ages ( $F$ s ranging from 6.9 to 9.7, $p$ s ranging from .003 to .001). In contrast, though the effect was significant when the analysis was performed for the entire sample of children, $F(2,231)=6.4, p<.01$, analyses performed for each age group individually failed to reveal any significant impact of training for the rotation test ( $F$ s ranging from .8 to $2.9, p$ s ranging from .14 to .43). Age was not significant, either as a main effect $(F<1)$ or in interaction with Training $(F<1)$.

The ANOVA showed a significant main Figure effect, $F(3,693)=5.9, p<.001$. Globally, the mean percentages of respect for the principle were slightly highest for the circle $(55.3 \%)$ and lowest for the rectangle $(50.6 \%)$. However, the Training by Figure interaction was not significant, $F(6,693)=1.4, p=.21$; neither was the Age by Training by Figure interaction, $F(24,693)=.53, p<1$. A similar impact of training was obtained, whatever the figure. Order was not significant, $F(1,231)=2, p=.16$, and neither were the interactions involving this factor, $p \mathrm{~s}<1$.

Explicit knowledge. As shown by an analysis of their free reports in the questionnaire phase, the children were unable to recollect any relevant information about the target manipulation. In the cued-recall test where they were required to state the starting point and the rotation direction as they remembered having seen them in the training phase, children who practiced in principle-conform training did not produce principle-conform responses more frequently than children who received principle-incongruent training $(49.5 \%$ against $50.8 \%, t(162)=-.43, p<1)$. No departure from chance level $(50 \%)$ was observed in either group, $t(82)=-.22$ or $t(81)=.39$, $p$ s $<1$. Thus, the 
Immediate Tests

Starting test

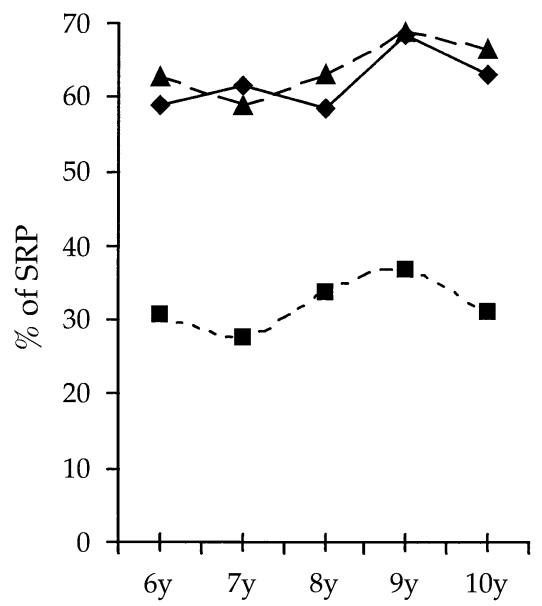

Rotation test

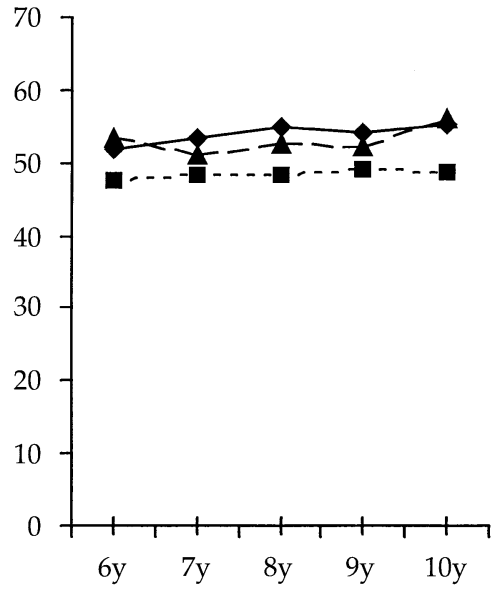

$$
\begin{aligned}
& \longrightarrow-\text { Principle-congr. } \\
& --\rightarrow-\text { Principle-incongr. } \\
& -\rightarrow-\text { - Control }
\end{aligned}
$$

Figure 1 Percentage respect of the SRP (start-rotation principle) in the immediate test phase as a function of age (6-10 years), training, and test.

postexperimental investigation failed to reveal any difference in the children's explicit knowledge, whether they received principle-congruent or principleincongruent training. In neither case did they notice any information relevant to the covariation between the starting location and the rotation direction.

\section{DISCUSSION}

Experiment 1 demonstrates that appropriately designed practice may lead children to modify a principlestructured drawing behavior. Using the NPP, this experiment failed to reveal any difference across ages in the way children implicitly learned a new drawing behavior. At all ages, principle-incongruent practice led to a large decrease in the production of drawing responses conforming to the principle when children were asked to select a rotation direction for a given starting position. Children's global pattern of results was very close to that observed in adults (Vinter \& Perruchet, 1999). These results lend support to the thesis that implicit learning processes are efficient from an early age and are age independent. They are consistent with our suggestion that the improvement with age of implicit learning abilities obtained in the Maybery, Taylor, and O'Brien-Malone (1995) study could have been due to contamination effects caused by explicit influences.

An alternative hypothesis, however, is worth examining for the Maybery et al. (1995) results. These authors contrasted a 5- to 7-year-old group with a 10to 12-year-old group, whereas the Meulemans et al. (1998) study and ours, which both concluded in favor of the age-independency assumption, dealt with children aged 6-10 years. The presence of children below 6 years in the Maybery et al. study may explain why age differences were observed in this study. It thus appears worth studying children younger than 6 years to explore further this question of the age sensitivity of the implicit learning processes.

Experiment 1 showed that two conditions provided no or weak evidence of learning in children aged 6-10 years. The principle-congruent practice had no impact on children's behavior, and the rotation test with principle-incongruent practice produced a significant learning effect only when the analysis was performed on the whole sample of children, which included 261 participants. These results can be accounted for as a ceiling effect. The baseline level of respect for the principle was already too high at 6 years to permit a sizeable increase. As shown by the control group in the initial free training task, around $69 \%$ on average of the 6-year-old children's 
production spontaneously conformed to the principle. The fact that the start-rotation principle was already high at 6 years can also account for the failure of the rotation test to reveal a clear-cut impact of training. The two movement parameters involved in the principle are already strongly related at 6 years, with the direction of movement being predominantly driven by the starting position (Van Sommers, 1984), with the result that the opposite influence cannot be easily elicited.

These arguments indicate that there is additional interest in extending the study to younger children. Indeed, the principle gains in strength between 4 and 10 years (Meulenbroek et al., 1993; Vinter \& Meulenbroek, 1993). Hence, if the failure of congruent training to have an impact on children's drawing behavior was also due to a ceiling effect between 6 and 10 years, the situation could be different in younger children. Similarly, the extent to which the rotational drawing movement might drive the starting location at an early age, before drawing ability attains a certain level of mastery, is questionable. Both aspects of movement indeed appear to be fairly undifferentiated at the beginning of drawing development, as illustrated by children aged around 2 years, who cover the graphic space with ballistic movements, tending to produce straight lines on the paper or scribbles (see, e.g., Lurçat, 1974). Four-year-old children still encounter some difficulties in drawing closed geometrical figures, showing that this ability is not perfectly mastered at this age. Thus, the study of 4- and 5-yearold children will make possible further testing of both the hypothesis of the age independence of implicit learning effects and the specific hypotheses formulated to account for the negative or weak learning effects recorded in some experimental conditions in older children, as in adults (Vinter \& Perruchet, 1999). Note that we also tried to include a 3-year-old age group in the study. However, the experimental situation was too constrained for such young children, who found it extremely difficult to trace over the tablet with the special pen. A paper-and-pencil test would be more convenient for this age group.

\section{EXPERIMENT 2}

\section{Method}

Participants. Fifty-four right-handed children participated in the second experiment. Handedness of these children was assessed by means of simple tests (Bryden, 1977). Eight items were used; four were unimanual (drawing, throwing a ball, holding scissors, and brushing one's teeth) and four were bimanual (shutting a bottle, hitting a nail with a hammer, lighting a match, and wiping a plate with a cloth). Only children who obtained a score equal or superior to 6 were selected. The children were aged 4 or 5 years, divided into 2 age groups $(M=4$ years: $n=24,14$ males, range $=3,10-4,2 ; M=5.1$ years: $n=30,14$ males, range $=4,10-5,3)$. In each age group, the children were randomly assigned to one of three subgroups that differed in their training phase: principle-congruent group, principle-incongruent group, and free control group. There were eight children in each group at 4 years, ten at 5 years. None of these children was educationally advanced or retarded or had psychomotor deficits in drawing. Each age group corresponded to one school level, the youngest children coming from the medium kindergarten grade and the 5-year-old children from the last kindergarten grade.

Material. The material used in this second experiment was the same as that described in Experiment 1. However, only two figures, the circle and the square, were presented for tracing. This avoided confronting young children with difficulties in the very act of tracing over the more complex figure (the triangle) and allowed us to shorten the duration of the experimental session to protect them from overtiredness.

Procedure. The procedure was the same as in Experiment 1 . The children were randomly assigned to one of three groups, a principle-incongruent group, a principle-congruent group, and a free control group, and were exposed to the same training conditions as in the previous experiment. Eighty percent of the figures (i.e., 16 out of 20) conformed to the start-rotation principle in the principle-congruent group against $20 \%$ in the principle-incongruent group. The children from the control group were free to trace over the set of 20 figures constituting the training phase. Then, the children from the three groups received two successive tests: a test using the starting location as a cue (20 items, 10 repetitions of each figure with 5 starting at the top and 5 starting at the bottom), followed by a test using the rotation direction as a cue (20 items, with five of each figure presenting a clockwise rotation and five a counterclockwise rotation). Only one order of test presentation was retained because pilot observations have revealed that young children have some difficulty in understanding the task instructions presented for the test using the rotation direction as a cue. In contrast, they exhibited no difficulty at all with the other test, which was thus systematically presented first to better capture the potential training effects.

Finally, the children from the principle congruent and incongruent groups also had to fill in the questionnaire and complete the cued-recall test, as described in Experiment 1. However, most of them did 
not understand the instructions for this latter test. Therefore, these data were discarded.

\section{RESULTS}

An ANOVA on the percentages of respect for the principle recorded in the test phase was carried out with Age (2) and Training (3) as between-subjects factors and Test (2) and Figure (2) as within-subjects factors. A significant impact of training appeared, $F(2,48)=13.8, p<.001$.

As shown by Figure 2, however, the Training by Test interaction reached significance, $F(2,48)=7.5, p<.01$. The impact of training was revealed in the starting location test, $F(2,48)=17, p<.001$, but not in the test using the rotation direction as a cue, $F(2,48)=1.5, p=$ .22. No main effect of Figure was obtained, $F<1$, and Figure did not interact with Training or Age, Fs $<1$.

The main finding emerging from a comparison between Experiment 1 and Experiment 2 was that a positive impact of training was induced after principlecongruent practice in the younger children, $F(1,48)=$
9.8, $p<.01$, but not in the older children, $F<1$. To check whether this difference could be due to minor experimental differences between the two experiments, we selected the data from Experiment 1 that was obtained with the starting location test when it occurred first, and for the circle and the square only. An ANOVA including Age (5) and Training (3) as between-subjects factors and Figure (2) as withinsubjects factor was run on these selected data. Training was significant, but the contrast between the principlecongruent group and the control group was not, $F<1$. The Age by Training interaction did not reach significance either, $F<1$. This confirms that congruent training has no effect in the 6- to 10year-old children.

\section{DISCUSSION}

Implicit learning processes of the type involved in our experimental situation are efficient from age 4 . Young children respected the start-rotation principle after principle-incongruent training less often than

\section{Immediate Tests}

Starting test

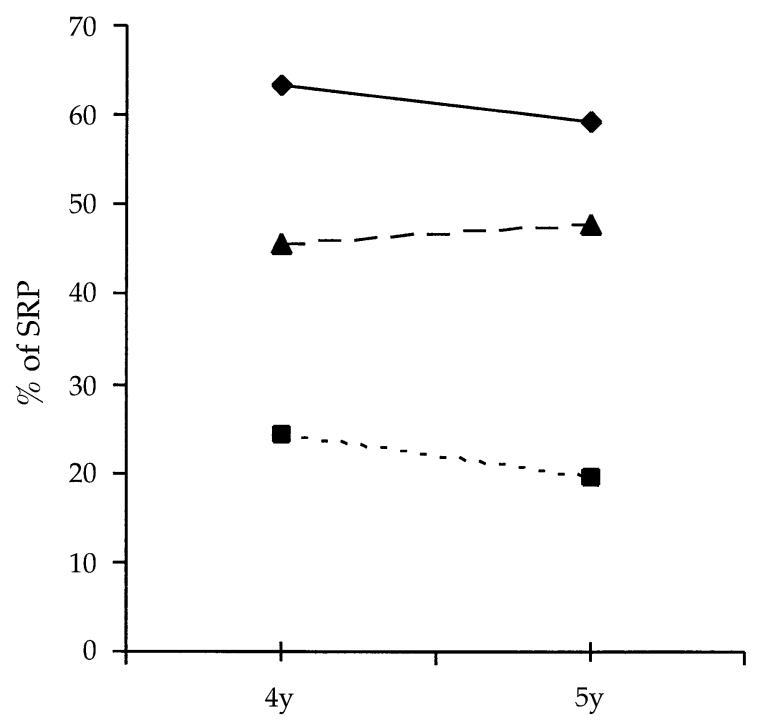

Rotation test

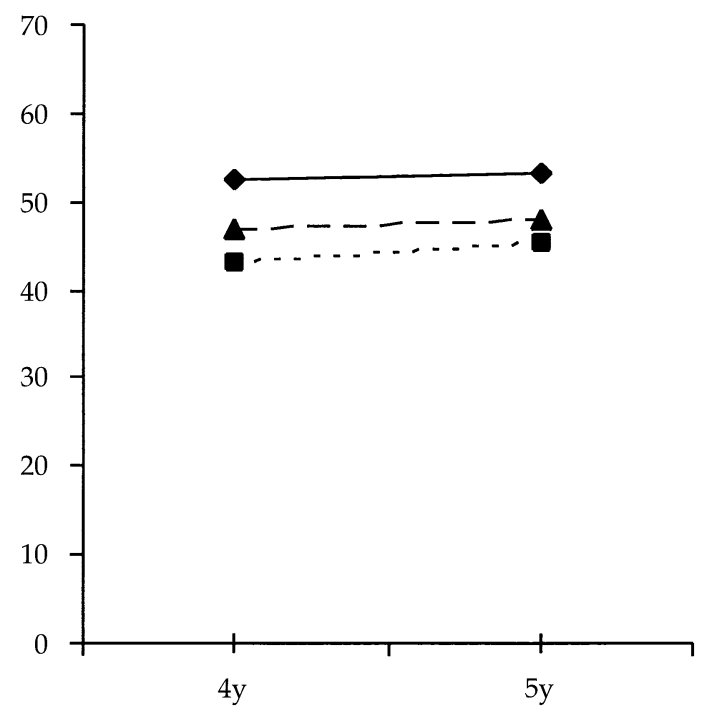

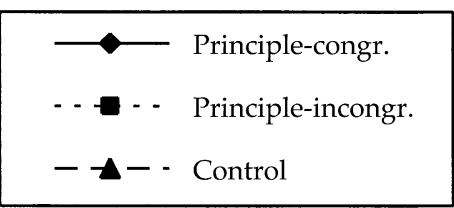

Figure 2 Percentage respect of the SRP (start-rotation principle) in the immediate test phase as a function of age (4 and 5 years), training, and test. 
control children did. In contrast to older children, they also tended to increase their degree of respect for the principle after principle-congruent practice. This result was expected on the basis of their spontaneous level for respect of the principle. As a matter of fact, the data from the control group in the free training phase showed that 4- to 5-year-old children spontaneously respected the principle in around $52 \%-54 \%$ of cases, that is, at a level clearly lower than that observed between 6 and 10 years (around $67 \%$ on average). Taking this baseline level into consideration, training at 20\% (predominantly principle-incongruent) and training at $80 \%$ (predominantly principlecongruent) should - a priori-have roughly the same impact because a similar difference exists between each type of training and the baseline condition. The results support this expectation. This means that the age differences observed between Experiments 1 and 2 do not reveal important differences in implicit learning abilities but are essentially a function of the baseline level of respect for the principle. The high baseline level in older children made a further increase in respect for the principle unlikely but left considerable room for a decrease. In contrast, the baseline in young children was close enough to random level to leave room for both an increase or decrease; however, because age covaries with this baseline level, we cannot exclude the possibility that other age-related factors are involved in the differences between young and older children.

Considering thus that these differences are not relevant for our purpose, Experiments 1 and 2 suggest that implicit learning processes are age independent. Such a conclusion, however, would be more compelling if we could include a comparison with older participants. A group of 54 adults has been studied by using exactly the same material, design, and procedure as those described in Experiment 1 (Vinter \& Perruchet, 1999). A first investigation of the Age effect across children and adults can thus be made by performing an ANOVA with Age (6), Training (3), and Order (2) as between-subjects factors and Test (2) and Figure (4) as within-subjects factors. Unsurprisingly, Training had a highly significant impact on the degree of respect for the principle, $F(2,279)=53.9, p<.001$, and the Training $\times$ Test interaction yielded significant results, $F(2,279)=33.5, p<.001$. Of focal interest, the Age $\times$ Training interaction did not have any significant effect, $F(10,279)=.14, p<1$, and the Age $\times$ Training $\times$ Test interaction also failed to reach any significance, $F(10,279)=.16, p<1$. Data obtained by children from the three trainings in the two tests are reported in Figure 1. The corresponding values for adults were the following: principle-congruent training: $62 \%$ and $52 \%$ (starting test and rotation test); principle-incongruent training: $27 \%$ and $51 \%$; control group: $63 \%$ and 57\% (see Vinter \& Perruchet, Experiment 1, 1999).

A more thorough investigation of the age effect can be carried out by selecting from the data collected in children aged 6-10 years and in adults those obtained in conditions presented to the younger children in Experiment 2 (namely the degree of respect for the principle for the circle and square, given only one order of administration of the tests, the starting location test first, the rotation test second). An ANOVA with Age (8: 4-10 years, adults) and Training (3) as between-subjects factors and Test (2) and Figure (2) as within-subjects factors was performed. Training had a strong impact, $F(2,191)=43.7, p<.001$, a percentage of respect for the principle of $60 \%, 39 \%$, and $57 \%$ being recorded in the principle-congruent training, the principle-incongruent training, and the control group, respectively. More importantly for the developmental issue, the impact of training did not vary significantly across ages, $F(14,191)=.40, p<1$, as can be seen in Table 1. Differentiating the results according to the nature of the test did not modify the conclusion: the Age $\times$ Training $\times$ Test interaction did not yield a significant effect, $F(14,191)=.38, p<1$. Table 1 also provides information about the variability of the effect depicted in Figures 1 and 2. As clear from the table, there are of course some individual differences in performance, but these differences did not vary systematically as a function of training. At almost each age, a majority of participants from the congruent training and from the control group followed the principle, whereas a majority of participants did not show adherence to the principle after the incongruent training.

In synthesis, whether we compare children aged 6-10 years and adults using the same design and procedure or children aged 4-10 years and adults on the basis of a selection of data for older participants for a better matching of conditions, we observed that implicit learning processes never varied as a function of age. However, developmental differences could still affect the implicit performances in a different way, for instance in relation to the duration of the impact of training. Experiment 3 was devoted to this issue.

\section{EXPERIMENT 3}

In Experiments 1 and 2, the test phase took place 4-5 min after the training session. In adults, the induced modifications of drawing behavior are preserved after a longer temporal lag, namely a 1-hr break (Vinter \& Perruchet, 1999). Although no relevant developmental differences appeared in Experiments 1 and 2, the learning effect could nevertheless be more 
Table 1 Experiments 1 and 2: Mean Degree of Respect for the Start-Rotation Principle as a Function of Training and Age

\begin{tabular}{|c|c|c|c|c|c|c|c|}
\hline \multirow{2}{*}{$\begin{array}{l}\text { Age } \\
\text { (Years) }\end{array}$} & \multirow[b]{2}{*}{ Training } & \multirow[b]{2}{*}{$n$} & \multicolumn{3}{|c|}{ Percent for Respect } & \multicolumn{2}{|c|}{$\begin{array}{c}\text { Number of } \\
\text { Participants }(\%)\end{array}$} \\
\hline & & & Means & $S D$ & Min-Max & $>50 \%$ & $<50 \%$ \\
\hline \multirow[t]{3}{*}{4} & congruent & 8 & 58 & .09 & $40-71$ & $6(75)$ & $2(25)$ \\
\hline & incongruent & 8 & 34 & .19 & $21-63$ & $3(37.5)$ & $5(62.5)$ \\
\hline & control & 8 & 48 & .16 & $27-73$ & $4(50)$ & $4(50)$ \\
\hline \multirow[t]{3}{*}{5} & congruent & 10 & 58 & .11 & $39-75$ & $9(90)$ & $1(10)$ \\
\hline & incongruent & 10 & 35 & .07 & $27-48$ & $0(0)$ & $10(100)$ \\
\hline & control & 10 & 49 & .13 & $27-73$ & $5(50)$ & $5(50)$ \\
\hline \multirow[t]{3}{*}{6} & congruent & 9 & 58 & .14 & $37-79$ & $6(66.7)$ & $3(33.3)$ \\
\hline & incongruent & 9 & 40 & .22 & $8-68$ & $2(22.2)$ & $7(77.8)$ \\
\hline & control & 9 & 58 & .20 & $21-83$ & $6(66.7)$ & $3(33.3)$ \\
\hline \multirow[t]{3}{*}{7} & congruent & 8 & 61 & .11 & $42-75$ & $7(87.5)$ & $1(12.5)$ \\
\hline & incongruent & 8 & 36 & .13 & $21-62$ & $1(12.5)$ & $7(87.5)$ \\
\hline & control & 8 & 53 & .12 & $41-79$ & $5(62.5)$ & $3(37.5)$ \\
\hline \multirow[t]{3}{*}{8} & congruent & 10 & 59 & .18 & $29-83$ & $8(80)$ & $2(20)$ \\
\hline & incongruent & 10 & 39 & .19 & $12-62$ & $4(40)$ & $6(60)$ \\
\hline & control & 10 & 62 & .17 & $29-83$ & $8(80)$ & $2(20)$ \\
\hline \multirow[t]{3}{*}{9} & congruent & 8 & 60 & .10 & $46-75$ & $7(87.5)$ & $1(12.5)$ \\
\hline & incongruent & 8 & 46 & .12 & $33-62$ & $3(37.5)$ & $5(62.5)$ \\
\hline & control & 8 & 64 & .16 & $33-83$ & $7(87.5)$ & $1(12.5)$ \\
\hline \multirow[t]{3}{*}{10} & congruent & 9 & 65 & .12 & $50-83$ & $9(100)$ & $0(0)$ \\
\hline & incongruent & 9 & 43 & .12 & $25-58$ & $4(44.4)$ & $5(55.6)$ \\
\hline & control & 9 & 64 & .14 & $33-79$ & $8(88.9)$ & $1(11.1)$ \\
\hline \multirow[t]{3}{*}{ Adults } & congruent & 10 & 61 & .14 & $37-75$ & $8(80)$ & $2(20)$ \\
\hline & incongruent & 10 & 39 & .11 & $25-58$ & $2(20)$ & $8(80)$ \\
\hline & control & 10 & 61 & .13 & $41-79$ & $7(70)$ & $3(30)$ \\
\hline
\end{tabular}

Note: Percentages (in parentheses) indicate portion of participants who shared a percentage of respect above or below $50 \%$.

unstable in children than in adults or in young children than in older children. Because 24 trials were used in each test, an analysis of the trials may provide some indications about the stability of the learning effect. In both experiments, Trials were never significant $(p s<1)$, and neither were the interactions between Trials and the other factors $(p s<1)$. This suggests that the impact of training was not localized in the first trials of the test phases only but lasted over the entire sessions. Experiment 3 was designed to test the extent to which the effect persisted after a 1-hr break between the training period and the test phase.

The results of Experiment 2 confirmed that the rotational test was not suited to revealing a clear impact of training on children's drawing behavior. The starting location seems to drive the rotational movement in drawing from an early age, even though the drawing of closed geometrical figures is still not completely mastered. Consequently, the rotational test was discarded in Experiment 3. It was replaced by a free test in which no indication was given in terms of starting point or direction of rotation. This free condition was added to examine whether the effect of directed practice was limited to the case where the same task context was reinstated (with similar instructions concerning the starting location) or was maintained in a free task.

\section{Method}

Participants. One hundred seventeen right-handed children participated in the experiment. They were aged between 4 and 10 years and were divided into five age groups $(M=4$ years: $n=21,10$ males, range $=$ $3,10-4,2 ; M=5.1$ years: $n=21,9$ males, range $=4,11-$ 5,$3 ; M=6.1$ years: $n=27,15$ males, range $=5,10-6,3$; $M=8$ years: $n=24,11$ males, range $=7,9-8,3 ; M=$ 10.1 years: $n=24,12$ males, range $=9,10-10,2)$. Note that we did not include a 7-year and a 9-year-old age group because no interesting developmental changes between 6 and 10 years requiring a fine-grained age sampling appeared in Experiment 1. The children of 
each age were randomly assigned to one of the three groups differing on the basis of their training phase: a principle-congruent group, a principle-incongruent group, and a free control group. There were between seven and nine children in each group. None of these children was educationally advanced or retarded or had psychomotor deficits in drawing or handwriting. Each age group corresponded to one school level, with the same correspondences as those mentioned in Experiment 1 and Experiment 2.

Material. The material was the same as that described in Experiment 1 for the children aged 6, 8, and 10 years (four figures used, rectangle, square, triangle, and circle) and the same as that described in Experiment 2 for the children aged 4 and 5 years (two figures used, circle and triangle).

Procedure. The procedure was also the same as used in the previous experiments. Children were randomly assigned to one of three groups - a principle congruent group, a principle incongruent group, and a free control group-and were exposed to the same training conditions as in the previous experiments ( 40 trials for children aged 6-10 years, 20 trials for the youngest children). However, unlike in Experiment 1 and 2, the test phase was run after a 1-hr break. In the test phase, all the children were first shown a set of either 24 figures (6-10 years) or 20 figures ( $4-5$ years) to trace over from an imposed starting point (no indication in terms of direction). Next, a second series of 24 or 20 figures was presented to the children, without any tracing constraints. Finally, as in the previous experiments, the children had to fill in a questionnaire and complete a postexperimental cued-recall test. However, the young children were again unable to complete the cued-recall test correctly and the data obtained from children aged below 6 years were therefore discarded from the analysis.

\section{Results}

Performance data. To obtain information on the impact of training across ages after a one-hour break, a global analysis was performed by using only the data for the circle and square because the 4-5 year-old children were trained on this subset of figures. An ANOVA with Age (5) and Training (3) as betweensubjects factors and Test (2) and Figure (2) as withinsubjects factors was performed. Figure 3 presents the mean percentages of respect for the principle obtained in the delayed test phase as a function of Age, Training, and Test, and Table 2 displays different indices of variability.

There was a strong impact of training after a 1-hr delay, $F(2,102)=16.1, p<.001$. On average across ages, children who received principle-congruent training respected the principle at $61.6 \%$, whereas those trained with noncongruent practice produced only $36.9 \%$ of drawings conforming to the principle. The corresponding performance of the control group concerned $58.1 \%$ of the trials. Age was significant, $F(4,102)=3.3, p<.05$, a global increase in the level of respect for the principle being observed across ages. This result is consistent with those reported in the literature (Meulenbroek et al., 1993; Vinter \& Meulenbroek, 1993). More important, the ANOVA did not reveal any significant Age $\times$ Training interaction, $F<1$. From 4-10 years of age, the impact of training was the same. Furthermore, as shown by Figure 3, no significant effect of Test was revealed, $F(1,102)=.64, p<1$, nor did Test interact with Training, $F(2,102)=1.69, p=$ .19 , or with Age $\times$ Training, $F(8,102)=.24, p<1$. The delayed impact of training was observed whether it was assessed on the starting location test, $F(1,102)=$ $13.9, p<.001$, or on the free test, $F(2,102)=7.6, p<$ .01 . Table 2 indicates that variability was not low, but it did not covary systematically with age or with training. We can wonder whether the absence of interaction between age and training may be due to this variability. Using a power analysis (Erdfelder, Faul, \& Buchner, 1996), we will later show that the amount of variability is not sufficient to account for this null effect.

Two additional analyses were performed separately for the 4- to 5-year-olds and the 6- to 10-yearolds. The first analysis (4- to 5-year-olds) revealed a marginally significant difference between the control group and the principle-congruent group, $F(1,36)=3$, $p=.09$, whereas significance was reached in Experiment 2. The second analysis (6- to 10-year-olds) was performed including the two figures (rectangle and triangle) that were not common to the young and older children. This did not yield any change in the results. After a 1-hr delay, training had still a clear effect on the drawing behavior of these older children, $F(2,66)=12.6, p<.001$, irrespective of whether the starting test, $F(2,66)=8.9, p<.001$, or the free test, $F(2,66)=6.2, p<.01$, was considered.

Explicit knowledge. Explicit knowledge was analyzed only in children aged 6-10 years. As in Experiment 1 , this postexperimental phase revealed that the children were unaware of the manipulation exercised during the training phase. In the cued-recall test, children from the principle-congruent group indicated the starting point and the rotation direction in conformity with the principle in $50.9 \%$ of cases. The corresponding value for children from the principle-incongruent group was $48.7 \%$. There was no significant difference in these percentages between the two groups, $t(48)=$ 
Delayed Tests

Starting test

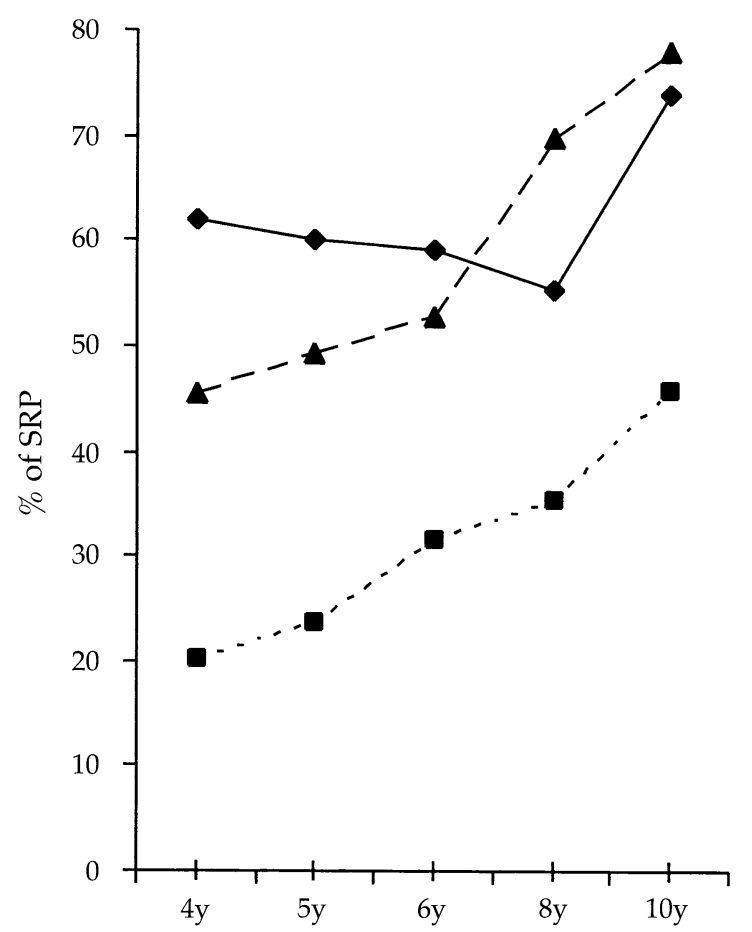

Free test

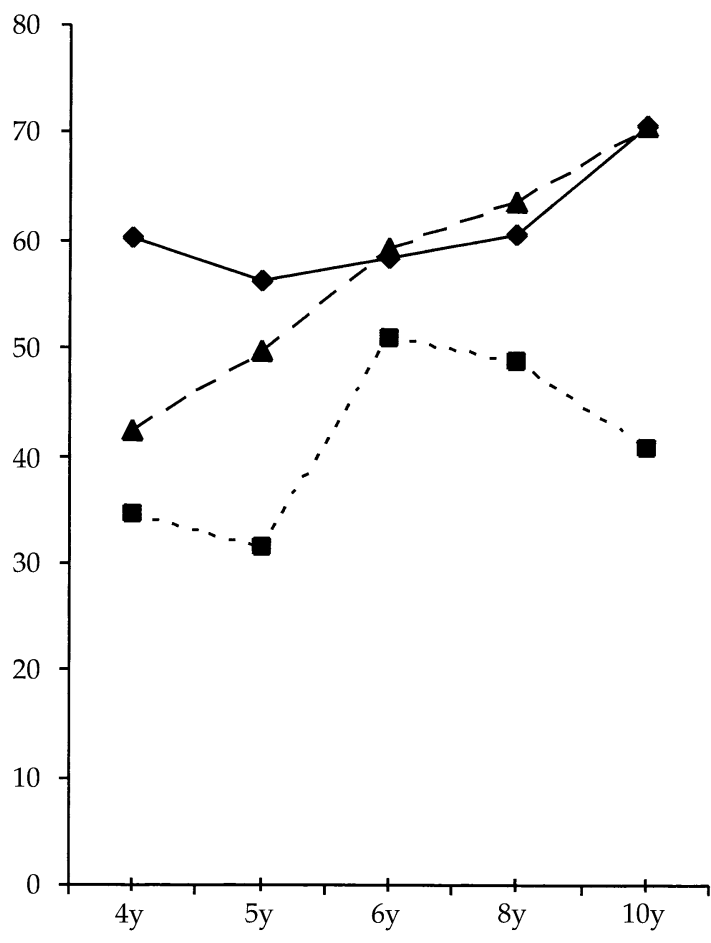

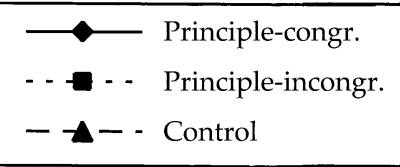

Figure 3 Percentage respect of the SRP (start-rotation principle) in the delayed test phase as a function of age (4-10 years), training, and test (selection of two figures: circle and square).

$.50, p<1$. Furthermore, these proportions did not differ from chance, $t(24)=.35$ or $t(24)=-.36, p s<1$.

\section{DISCUSSION}

Experiment 3 showed that the modifications in drawing behavior induced by specifically designed practice were still present after a 1-hr delay. Whether they were tested immediately or after a 1-hr break, children from 4-10 years produced significantly fewer responses conforming to the start-rotation principle after principle-incongruent training than after the control condition or a principle-congruent training. The effect was the same across ages. The finding of the persistence of the effect over time is consistent with earlier results reported in the literature on implicit learning, obtained with other types of experimental situations involving adults (Allen \& Reber,
1980; Nissen et al., 1989) as well as children (Meulemans et al., 1998).

The delay we explored in the present experiment may appear relatively short when compared with those tested in the literature. Evidence for incidentally induced behavioral modifications has been recorded even after 2 years (Allen \& Reber, 1980), although a more recent study failed to obtain long-term retention, after a 1-year delay, on a serial response time task (Willingham \& Dumas, 1997). How persistent the effect observed in our experiments may be is an empirical question that could be investigated in further experiments. Our findings, however, are sufficient to exclude any interpretation of the phenomenon in terms of immediate facilitating effects operating in the very short term because of the repetition of the same types of movements.

A positive impact of principle-congruent practice 
Table 2 Experiment 3: Mean Degree of Respect for the Start-Rotation Principle as a Function of Training and Age

\begin{tabular}{|c|c|c|c|c|c|c|c|}
\hline \multirow{2}{*}{$\begin{array}{l}\text { Age } \\
\text { (Years) }\end{array}$} & \multirow[b]{2}{*}{ Training } & \multirow[b]{2}{*}{$n$} & \multicolumn{3}{|c|}{ Percent for Respect } & \multicolumn{2}{|c|}{$\begin{array}{c}\text { Number of } \\
\text { Participants }(\%)\end{array}$} \\
\hline & & & Means & $S D$ & Min-Max & $>50 \%$ & $<50 \%$ \\
\hline \multirow[t]{3}{*}{4} & congruent & 7 & 61 & .27 & $25-97$ & $4(57.1)$ & $3(42.9)$ \\
\hline & incongruent & 7 & 27 & .21 & $8-58$ & $2(27.5)$ & $5(72.5)$ \\
\hline & control & 7 & 44 & .15 & $16-58$ & $3(42.9)$ & $4(57.1)$ \\
\hline \multirow[t]{3}{*}{5} & congruent & 7 & 58 & .18 & $41-84$ & $4(57.1)$ & $3(42.9)$ \\
\hline & incongruent & 7 & 28 & .15 & $8-44$ & $0(0)$ & $7(100)$ \\
\hline & control & 7 & 49 & .18 & $27-75$ & $3(42.9)$ & $4(57.1)$ \\
\hline \multirow[t]{3}{*}{6} & congruent & 9 & 59 & .22 & $29-91$ & $7(77.7)$ & $2(22.3)$ \\
\hline & incongruent & 9 & 41 & .15 & $25-66$ & $3(33.3)$ & $6(66.7)$ \\
\hline & control & 9 & 56 & .12 & $37-79$ & $5(55.5)$ & $4(44.5)$ \\
\hline \multirow[t]{3}{*}{8} & congruent & 8 & 58 & .22 & $25-87$ & $5(62.5)$ & $3(37.5)$ \\
\hline & incongruent & 8 & 42 & .20 & $12-75$ & $2(25)$ & $6(75)$ \\
\hline & control & 8 & 66 & .30 & $14-95$ & $6(75)$ & $2(25)$ \\
\hline \multirow[t]{3}{*}{10} & congruent & 8 & 72 & .18 & $50-91$ & $8(100)$ & $0(0)$ \\
\hline & incongruent & 8 & 43 & .27 & $4-79$ & $3(37.5)$ & $5(62.5)$ \\
\hline & control & 8 & 74 & .20 & $37-96$ & $6(75)$ & $2(25)$ \\
\hline
\end{tabular}

Note: Percentages (in parentheses) indicate portion of participants who shared a percentage of respect above or below $50 \%$.

on the drawing behavior of young children after a 1-hr delay was observed but the effect failed to reach significance. The magnitude of the effect was lower in the present experiment than in Experiment 2. This result could be due to two factors that are hard to disentangle. The phenomenon itself may be elusive and hard to replicate or it may be more sensitive to time than the opposite effect (impact of principle-incongruent training). For the present, we are unable to produce any argument in favor of one hypothesis or the other.

There were no significant differences between the starting location test and the free test with regard to the impact of training, although the amplitude of the effect appeared slightly lower with the free test. Thus, the behavioral modifications induced by an implicit learning session are not strictly linked to certain surface aspects of the situation, in our case the presence of imposed starting locations. Despite the fact that the resemblance between the training test and the test phase was less with the free test, the children still exhibited an impact of their earlier practice, thus revealing that what they have implicitly learned can be generalized across situations.

\section{GENERAL DISCUSSION}

Three experiments on implicit learning in children were conducted by using the NPP, in which unconscious influences are assessed on behavioral parame- ters that are neutral with regard to task achievement and different from those on which the task demands focus (Vinter \& Perruchet, 1999). Figure drawing behavior provides a convenient implementation for the procedure because the covariation between the starting location and the direction of rotation is easy to manipulate through the use of an appropriately designed practice phase. In the present series of experiments, children tended to invert the direction of rotation predominantly associated with a starting location after having been incidentally trained to respect the reverse covariation. No substantial difference relating to the impact of learning was observed between 6 and 10 years of age (Experiment 1 and 3). The comparison was extended to 4- to 5-year-olds (Experiment 2 and 3) and, again, no age effect appeared, even when a comparison with adults was considered (Experiment 2). This result is in line with the Meulemans et al. study (1998).

More precautions must be taken, however, before accepting the null hypothesis. To ensure that the absence of age effect on implicit learning was not due to our sample size, we computed a power analysis on the data presented in Table 1 (Experiments 1 and 2). The crucial effect pertained to the Age by Training interaction. Using eta2 as an index of effect size, we obtained a coefficient of .0293 , a value that does not even reach what Cohen (1988) defined as a small effect size (.10). The power analysis (Erdfelder et al., 1996) 
showed that to conclude for a significant interaction (with $\alpha=.05$ ) with a power level of .80, a sample size of 21,373 participants would be needed. A similar analysis was run on the data recorded in Experiment 3 (see Table 2). An effect size of the Age by Training interaction of .0486 was obtained. The analysis revealed that a sample of 6,368 participants would be required for attaining a significant interaction with a power level of .80. Thus, in both cases, endorsing the null hypothesis appears acceptable.

Consequently, the present experiments provide support for two of Reber's assumptions: first, that implicit learning processes are efficient from an early age, and second, that they are age independent. A similar conclusion can be drawn from studies on implicit memory (e.g., Graf, 1990; Schacter \& Moscovitch, 1984). Evidence for the age sensitivity of performance in some implicit learning situations has been reported, however (Maybery et al., 1995). This effect may be due to the interfering intervention of explicit influences, which can never be totally ruled out in most of the classical learning paradigms (Shanks \& St. John, 1994). The use of the NPP prevented such interference. The age effect obtained in Maybery et al. (1995) may also be due to specific difficulties encountered by young children in coping with the learning situation (e.g., limits in the understanding of the task instructions, which may have elicited some motivational or attentional problems). Implicit learning mechanisms may very well be sensitive to such behaviorally relevant factors. The advantage of the way the NPP was implemented in the drawing task was the simplicity of the learning task and its comparability across ages.

Note, however, that an alternative account (we thank an anonymous reviewer of a previous version of this paper for having suggested this alternative explanation) for the positive effect of age in the Maybery et al. (1995) study can be suggested. The behavior manipulated in our experiments associates a start position and a movement direction. Although these two variables can be manipulated independently through instructions, they are nonetheless two components naturally linked in a single perceptionaction unit. In Maybery et al.'s study, in contrast, the two features of the task that covaried were the location of a picture in a $4 \times 4$ matrix and the side of approach by the experimenter. These features seem clearly to be "nonintegral" (Garner, 1974) components of the task, arbitrarily linked for experimental purposes. It could be that age differences in implicit learning are more likely to occur when associations concern nonintegral than integral features. This hypothesis opens an interesting perspective for further research.
Evidencing the age invariance of implicit learning processes has potentially important consequences for developmental issues. Note that this result is consistent with Karmiloff-Smith's (1992) model of development, in which the first level is attained as a result of the action of implicit, data-driven processes. These processes contribute to the formation of implicit representations, which drive the children's progressively efficient adaptation to the world. These implicit representations reflect the main structural features of the experienced situations, and a representational redescription process will further make this knowledge successively explicit, conscious, and verbalizable. In this model, the first level is reached whenever a sufficient quantity of experiences related to a particular performance has been accumulated, independently of any age constraint. Hence, implicit learning processes are necessarily age insensitive in this view.

More generally, showing that implicit learning processes operate efficiently throughout development challenges any nativist conception (see, for instance, Spelke, Breinlinger, Macomber, \& Jacobson, 1992). Indeed, a landmark of the literature on implicit learning is that these processes allow people to become sensitive to the complex structure of the environmentand not only to its most simple, surface features. This literature is marked by lively debates about the mechanisms involved to account for this structural sensitivity, but the to-be-explained phenomenon itself is empirically well grounded and has never been questioned. As a consequence, implicit learning processes, whatever their specific nature, turn out to be capable of accounting for the very same abilities that once seemed to depend on innate predispositions.

Finally, evidencing the fundamental role of implicit processes in development should encourage developmentalists to consider the literature on implicit learning and contribute to the various debates that characterize this domain. Most of the questions raised in the implicit learning field are relevant from a developmental perspective. In the remainder of this discussion, we shall consider some of the results of our experiments while integrating perspectives derived from developmental models and from the implicit learning domain of research.

\section{The Dissociation Issue}

One important issue concerns the relationships between the participant's behavioral adaptation to a complex situation and the relevant corresponding explicit knowledge. In our experiments, the children remained unaware of the behavioral manipulation performed during the learning phase, in the same 
way as adult participants (Vinter \& Perruchet, 1999). This result lends support to the view that argues for a dissociation between performance and explicit knowledge, a view encountered in developmental research (e.g., Karmiloff-Smith, 1992; Mandler, 1992, 1998) as well as in the implicit learning area (e.g., Berry \& Broadbent, 1984; Nissen \& Bullemer, 1987; Reber, 1967).

Important doubts have been cast on the existence of a dissociation in the implicit learning literature. A close relation between performance and explicit knowledge has often been reported in experiments using standard conditions such as the artificial grammar paradigm (Dulany et al., 1984; Perruchet \& Pacteau, 1990) or serial reaction time tasks (Shanks \& Johnstone, 1998). Furthermore, most of the results advanced in favor of dissociation have been reinterpreted by Shanks and St. John (1994) in the light of the two criteria that a reliable test of explicit knowledge must satisfy, namely the information criterion (the information tapped by the explicit test and that responsible for the behavioral changes must be exactly the same ) and the sensitivity criterion (the explicit test must be sensitive to all the relevant conscious knowledge). Shanks and St. John (1994) have cogently shown that dissociation has not been proved because most of the studies failed to respect these criteria.

In our case, the NPP ensures a priori that participants will not exploit any relevant explicit knowledge to cope with the situation because even if they were to become aware of it in the course of learning, this knowledge could not bring any clear adaptive advantage enabling them to succeed in the task. Furthermore, although we cannot exclude the possibility that it does not totally fulfil the criteria defined by Shanks and St. John (1994), our cued-recall test nevertheless appears satisfactory. The type of knowledge to be investigated in the task involves a simple association between two parameters, without any evident correlated knowledge that might interfere during the learning process. The cued-recall test directly taps the association of interest between the two parameters. The simplicity of this situation means that the information criterion is easily fulfilled. With respect to the sensitivity criterion, our test does not present any particular advantage in comparison with other recall tests. Two arguments, however, lend support to the claim that our results are not due to a lack of sensitivity. Firstly, coherent results have been collected across a very large number of participants in different experiments, namely 356 children (excluding the 4- and 5year-olds who did not pass the explicit test) and 75 adults. In all of these experiments, a lack of relevant explicit knowledge was reported. Secondly, a strong effect of practice on performance was always observed, despite this absence of explicit knowledge. Thus, the demonstration that participants remained unaware of the behavioral manipulation appears compelling, as does the existence of a dissociation between performance and explicit knowledge. Note, however, that how explicit knowledge is usually investigated in implicit learning tasks can be questioned. There is a huge difference between the remembering of a previous experience - this is what is investigated in the classical explicit tests-and the fact that one's conscious experience of a present situation is influenced by a previous experience. Consider the artificial grammar paradigm for instance. The modification of behavior in the test phase, as attested to by the fact that some strings are perceived by subjects as being more grammatical than others, testifies to the modification of the way in which the material is consciously perceived. In this perspective, there is absolutely no dissociation between performance and conscious perception of the present situation. Now, questioning participants about the presence or absence of such strings in the previously viewed list is equivalent to investigating their explicit memory of the situation. This latter might be accurate or confused, complete or partial, depending on contextual factors. As a consequence, dissociation between performance and explicit knowledge, that is, the explicit memory of the learning task, might be found or not. In other words, it is important to distinguish between changes in our conscious experience of the world and the formation of a knowledge base about this world. Explicit recall or recognition tests tap this knowledge concerning a given situation experienced in the past.

\section{The Implicit Knowledge Issue}

Whenever explicit knowledge was unable to account for changes in performance, most authors subscribed to the idea that these changes were due to the formation of implicit knowledge. Several developmental models claim that implicit learning processes contribute to the formation of an inaccessible and unconscious basis of knowledge, which is thought to be implicit (Karmiloff-Smith, 1992; see, however, Vinter \& Perruchet, 1994) or procedural (Mandler, 1998). This view is shared by most authors from the implicit learning field (e.g., Lewicki et al., 1992; Mathews, 1990; Reber, 1993). In our situation, the children may have acquired a tacit knowledge of the covariation between starting point and direction of rotation that they experienced during training and then applied this knowledge in the subsequent test conditions.

However, it is worth stressing that if such reasoning 
can be applied in traditional paradigms, it is excluded in the case of the use of the NPP: There is, a priori, no more reason to exploit implicit as opposed to explicit knowledge of the new covariation between the two movement parameters because this knowledge shows itself no more adaptive than that which might possibly support the inverse covariation. The NPP undermines the plausibility of any explanation involving the formation and use of knowledge. It could be argued that implicit knowledge emerges nevertheless because implicit learning processes are responsive to all environmental variations, whatever the adaptive value of the resulting behavioral change. Such a view would, however, run counter to a dominant idea in the implicit learning field according to which implicit processes are highly adaptive.

If the formation of an implicit knowledge base is questionable, how can we account for the observed changes in performance? In our view, improvement in performance in implicit learning settings may be due to changes in the unconscious processes involved in coping with the task, as an automatic by-product of their involvement (see Kolers \& Roediger, 1984, for a similar procedularist view of mind). Implicit learning shapes the perceptions a participant develops of a situation through the direct and continuous tuning of the processes devoted to the treatment of incoming information. These processes operate associatively with the elements, which belong to the same attentional focus, being grouped together. They thus provoke changes in the way information is encoded, and these changes directly affect the participant's phenomenal experience through the formation of new processing cognitive units (Perruchet \& Vinter, 1998, 1999; Perruchet, Vinter, \& Gallego, 1997).

Replacing the idea of the formation of an implicit knowledge base with that of the tuning of unconscious processes is not a purely terminological issue. A recent study on the priming of new associations (Poldrack \& Cohen, 1997) allows us to make both the nature and the implications of this change clearer. A priori, the improvement in the reading time of repeated word pairs would appear to be due to the knowledge that two words have been associated in the past. Poldrack and Cohen (1997), however, have shown that the simple interposition of the word and between the paired words eliminates the pairing-specific effect. This effect is evidently not consistent with the formation of a knowledge base. The authors suggest that associative priming may be partly mediated by the learning of how to program the musculature to coarticulate a pair of words most efficiently. This study illustrates how changes in intrinsically unconscious processes may be a valuable alternative to the formation of an implicit knowledge base. Regarding figure drawing, a processing unit may drive both the starting point and the rotation direction as indissociable parameters. The changes in the processes that permit the formation of this processing unit are completely unrelated to the formation of implicit covariation knowledge (in the same way that the improved ability to program the transition between syllables straddling word boundaries is unrelated to any knowledge about the sequence of these words in the language). What has really changed, however, in the way information is processed in our drawing situation remains unclear. In particular, the possible roles of perception and action have to be disentangled. Would participants modify their behavior even if they did not perform any drawing movements in the learning phase? Such experiments are currently in progress.

In conclusion, the efficiency, from an early age, of implicit learning processes in making children's behavior sensitive to the main structural aspects of the environment, independently of any intention to learn these aspects, offers a real challenge to developmentalists who wish to understand how children learn about their environment - and what they learn. Integrating research into implicit learning within a developmental perspective should be a fruitful way of better understanding how behaviors evolve in the course of development.

\section{ACKNOWLEDGMENTS}

This work has been supported by the University of Burgundy, the Region of Burgundy (project 2AFE), and the Centre National de la Recherche Scientifique (CNRS, ESA 5022). The authors would like to thank Dominique Rigaudière and Romain Raffin, who wrote the $C$ programs used to run the experiments.

\section{ADDRESSES AND AFFILIATIONS}

Corresponding author: Annie Vinter, Laboratoire d'Étude des Apprentissages et du Développement (L.E.A.D.), CNRS ESA 5022, Université de Bourgogne, Faculté des Sciences, 6 bv. Gabriel, 21000 Dijon, France; e-mail: annie.vinter@u-bourgogne.fr. Pierre Perruchet is also at L.E.A.D.

\section{REFERENCES}

Allen, R., \& Reber, A. S. (1980). Very long term memory for tacit knowledge. Cognition, 8, 175-185.

Bates, E., \& Elman, J. (1996). Learning rediscovered. Science, $274,1849$.

Berry, D. C. (1994). Implicit learning: Twenty-five years on. In C. Umilta \& M. Moscovitch (Eds.), Attention and Per- 
formance XV: Conscious and nonconscious information processing. Cambridge, MA: MIT Press.

Berry, D. C., \& Broadbent, D. E. (1984). On the relationship between task performance and associated verbalizable knowledge. The Quarterly Journal of Experimental Psychology, 36A, 209-231.

Berry, D. C., \& Dienes, Z. (1993). Implicit learning: Theoretical and empirical issues. Hove, U.K.: Erlbaum.

Bruner, J. S., Goodnow, J. J., \& Austin, G. A. (1956). A study of thinking. New York: Wiley.

Bryden, M. P. (1977). Measuring handedness with questionnaires. Neuropsychologia, 15, 611-624.

Carr, T. H., \& Curran, T. (1994). Cognitive factors in learning about structured sequences. Studies in Second Language Acquisition, 16, 205-230.

Chandler, S. (1993). Are rules and modules really necessary for explaining language? Journal of Psycholinguistic Research, 22, 593-606.

Cleeremans, A. (1993). Mechanisms of Implicit Learning: A connectionist model of sequence processing. Cambridge, MA: MIT Press / Bradford Books.

Cohen, J. (1988). Statistical power analysis for the behavioral sciences (2nd ed.). New York: Academic Press.

Dulany, D. E. (1997). Consciousness in the explicit (deliberative) and implicit (evocative). In J. D. Cohen \& J. W. Schooler (Eds.), Scientific approaches to the study of unconsciousness. Mahwah, NJ: Erlbaum.

Dulany, D. E., Carlson, R. A., \& Dewey, G. I. (1984). A case of syntactical learning and judgment: How conscious and how abstract? Journal of Experimental Psychology: General, 113, 541-555.

Elman, J. L., Bates E. A., Johnson, M. H., Karmiloff-Smith, A., Parisi, D., \& Plunkett, K. (Eds.). (1996). Rethinking innateness. Cambridge, MA: MIT Press.

Erdfelder, E., Faul, F., \& Buchner, A. (1996). GPower: A general power analysis program. Behavior Research Methods, Instruments, and Computers, 28, 1-11.

Garner, N. R. (1974). The processing of information and structure. Potomac, MD: Erlbaum.

Gomez, R. L., \& Gerken, L. (1999). Artificial grammar learning by 1-year-olds leads to specific and abstract knowledge. Cognition, 70, 109-135.

Graf, P. (1990). Life-span changes in implicit and explicit memory. Bulletin of the Psychonomic Society, 28, 353-358.

Howard, D. V., \& Howard, J. H., Jr. (1989). Age differences in learning serial patterns: Direct versus indirect measures. Psychology and Aging, 4, 357-364.

Howard, D. V., \& Howard, J. H., Jr. (1992). Adult age differences in the rate of learning serial patterns: Evidence from direct and indirect tests. Psychology and Aging, 7, 232-241.

Jacoby, L. (1991). A process dissociation framework: Separating automatic from intentional uses of memory. Journal of Memory and Language, 30, 513-541.

Kail, R. V. (1990). The development of memory in children. New York: Freeman.

Karmiloff-Smith, A. (1992). Beyond modularity: A developmental perspective on cognitive science. Cambridge, MA: MIT Press.
Kolers, P. A., \& Roediger, H. L. (1984). Procedures of mind. Journal of Verbal Learning and Verbal Behavior, 23, 425-449.

Krist, H., Fieberg, E. L., \& Wilkening, F. (1993). Intuitive physics in action and judgment: The development of knowledge about projective motion. Journal of Experimental Psychology: Learning, Memory and Cognition, 19, 952-966.

Lewicki, P. (1986). Nonconscious social information processing. Orlando, FL: Academic Press.

Lewicki, P., Hill, T., \& Czyzewska, M. (1992). Nonconscious acquisition of information. American Psychologist, 47, 796-801.

Lurçat, L. (1974). Etude de l'acte graphique. Mouton: Paris.

Mandler, J. M. (1992). How to build a baby: II. Conceptual primitives. Psychological Review, 99, 587-604.

Mandler, J. M. (1998). Representation. In D. Kuhn \& R. Siegler (Eds.), W. Damon (Series Ed.), Handbook of child psychology: Vol. 2. Cognition, perception, and language. New York: Wiley.

Mathews, R. C. (1990). Abstractness of implicit grammar knowledge: Comments on Perruchet and Pacteau's analysis of synthetic grammar learning. Journal of Experimental Psychology: General, 119, 412-416.

Maybery, M., \& O’Brien-Malone, A. (1998). Implicit and automatic processes in cognitive development. In $\mathrm{K}$. Kirsner, C. Speelman, M. Maybery, A. O’Brien-Malone, M. Anderson, \& C. MacLeod (Eds.), Implicit and explicit mental processes. Mahway, NJ: Erlbaum.

Maybery, M., Taylor, M., \& O’Brien-Malone, A. (1995). Implicit learning: Sensitive to age but not IQ. Australian Journal of Psychology, 47, 8-17.

Merikle, P. M., \& Joordens, S. (1997). Measuring unconscious influences. In J. D. Cohen \& J. W. Schooler (Eds.), Scientific approaches to consciousness. Mahwah, NJ: Erlbaum.

Meulemans, T., Van der Linden, M., \& Perruchet, P. (1998). Implicit sequence learning in children. Journal of Experimental Child Psychology, 69, 199-221.

Meulenbroek, R., Vinter, A., \& Mounoud, P. (1993). Development of the start-rotation principle in circle production. British Journal of Developmental Psychology, 11, 307-320.

Munakata, Y., McClelland, J. L., Johnson, M. H., \& Siegler, R. S. (1997). Rethinking infant knowledge: Toward an adaptive process account of successes and failures in object permanence tasks. Psychological Review, 104, 686713.

Myers, C., \& Conner, M. (1992). Age differences in skill acquisition and transfer in an implicit learning paradigm. Applied Cognitive Psychology, 6, 429-442.

Nissen, M. J., \& Bullemer, P. (1987). Attentional requirements of learning: Evidence from performance measures. Cognitive Psychology, 19, 1-32.

Nissen, M. J., Willingham, D., \& Hartman, M. (1989). Explicit and implicit remembering: When is learning preserved in amnesia? Neuropsychologia, 27, 341-352.

Perruchet, P., \& Pacteau, C. (1990). Synthetic grammar learning: Implicit rule abstraction or explicit fragmentary knowledge? Journal of Experimental Psychology: General, 119, 264-275.

Perruchet, P., \& Vinter, A. (1998). Learning and development. The Implicit knowledge assumption reconsidered. 
In M. Stadler \& P. Frensch (Eds.), Handbook of implicit learning. Thousands Oaks, CA: Sage.

Perruchet, P., Vinter, A., \& Gallego, J. (1997). Implicit learning shapes new conscious percepts and representations. Psychonomics Bulletin and Review, 4, 43-48.

Poldrack, R. A., \& Cohen, N. J. (1997). Priming of new associations in reading time: What is learned? Psychonomic Bulletin \& Review, 4, 398-402.

Reber, A. S. (1967). Implicit learning of artificial grammars. Journal of Verbal Learning and Verbal Behavior, 6, 855-863.

Reber, A. S. (1989). Implicit learning and tacit knowledge. Journal of Experimental Psychology: General, 118, 219-235.

Reber, A. S. (1993). Implicit learning and tacit knowledge: An essay on the cognitive unconscious. New York: Oxford University Press.

Reber, P., \& Lewis, S. (1977). Toward a theory of implicit learning: The analysis of the form and structure of a body of tacit knowledge. Cognition, 5, 333-361.

Saffran, J. R., Johnson, E. K., Aslin, R. N., \& Newport, E. L. (1999). Statistical learning of tone sequences by human infants and adults. Cognition, 70, 27-52.

Saffran, J. R., Newport, E. L., Aslin, R. N., Tunick, R. A., \& Barrueco, S. (1997). Incidental language learning. Psychological Science, 8, 101-105.

Schacter, D. L., \& Moscovitch, M. (1984). Infants, amnesiacs, and dissociable memory systems. In M. Moscovitch (Ed.), Infant memory: Its relation to normal and pathological memory in humans and other animals. New York: Plenum.

Schyns, P. G., Goldstone, R. L., \& Thibaut, J. P. (1998). The development of features in object concepts. Behavioral and Brain Sciences, 21, 1-53.

Schyns, P. G., \& Rodet, L. (1997). Categorization creates functional features. Journal of Experimental Psychology: Learning, Memory E Cognition, 23, 681-696.

Seger, C. A. (1994). Implicit learning. Psychological Bulletin, 115, 163-196.

Shanks, D. R., \& Johnstone, T. (1998). Implicit knowledge in sequential learning tasks. In M. Stadler \& P. Frensch (Eds.), Handbook of implicit learning. Thousands Oaks, CA: Sage.

Shanks, D. R., \& St. John, M. (1994). Characteristics of dissociable human learning systems. Behavioral and Brain Science, 17, 367-447.

Spelke, E. S., Breinlinger, K., Macomber, J., \& Jacobson, K. (1992). Origins of knowledge. Psychological Review, 99, 605-632.

Thelen, E., \& Smith, L. B. (Eds.). (1994). A dynamic systems approach to the development of cognition and action. Cambridge, MA: MIT Press.

Van Sommers, P. (1984). Drawing and Cognition. Cambridge, U.K.: Cambridge University Press.

Vinter, A., \& Meulenbroek, R. (1993). The role of manual dominance and visual feedback in circular drawing movements. Journal of Human Movement Studies, 25, 11-37.

Vinter, A., \& Perruchet, P. (1994). Is there an implicit level of representation? Behavioral and Brain Sciences, 17, 415416.

Vinter, A., \& Perruchet, P. (1999). Isolating unconscious influences: The neutral parameter procedure. The Quarterly Journal of Experimental Psychology, 4, 857-875.

Willingham, D. B., \& Dumas, J. A. (1997). Long-term retention of a motor skill: Implicit sequence knowledge is not retained after a one-year delay. Psychological Research, 60, 113-119. 